\title{
Proteomic Signatures of the Zebrafish (Danio rerio) Embryo: Sensitivity and Specificity in Toxicity Assessment of Chemicals
}

\author{
Karen Hanisch, Eberhard Küster, Rolf Altenburger, and Ulrike Gündel \\ Department of Bioanalytical Ecotoxicology, Helmholtz Centre for Environmental Research-UFZ, \\ Permoser Straße 15, 04318 Leipzig, Germany \\ Correspondence should be addressed to Ulrike Gündel, ulrike.guendel@ufz.de
}

Received 18 February 2010; Revised 26 May 2010; Accepted 19 July 2010

Academic Editor: Uwe Völker

Copyright ( $\odot 2010$ Karen Hanisch et al. This is an open access article distributed under the Creative Commons Attribution License, which permits unrestricted use, distribution, and reproduction in any medium, provided the original work is properly cited.

\begin{abstract}
Studies using embryos of the zebrafish Danio rerio (DarT) instead of adult fish for characterising the (eco-) toxic potential of chemicals have been proposed as animal replacing methods. Effect analysis at the molecular level might enhance sensitivity, specificity, and predictive value of the embryonal studies. The present paper aimed to test the potential of toxicoproteomics with zebrafish eleutheroembryos for sensitive and specific toxicity assessment. 2-DE-based toxicoproteomics was performed applying low-dose $\left(\mathrm{EC}_{10}\right)$ exposure for $48 \mathrm{~h}$ with three-model substances Rotenone, 4,6-dinitro-o-cresol (DNOC) and Diclofenac. By multivariate "pattern-only" PCA and univariate statistical analyses, alterations in the embryonal proteome were detectable in nonetheless visibly intact organisms and treatment with the three substances was distinguishable at the molecular level. Toxicoproteomics enabled the enhancement of sensitivity and specificity of the embryonal toxicity assay and bear the potency to identify protein markers serving as general stress markers and early diagnosis of toxic stress.
\end{abstract}

\section{Introduction}

As fish are highly developed vertebrates in the aquatic ecosystems, they are of major relevance in ecotoxicology mainly as important model organisms for toxicity assessment of water pollution. The acute fish test, for example, [1] is among the base test set necessary for regulatory risk assessment of chemicals. Among fish, the zebrafish (Danio rerio), a small tropical fish native to rivers of India and South Asia [2], has emerged as a popular vertebrate model in (eco-) toxicology [3-5] because it is unique with respect to the level of available knowledge and technology and has many benefits like its rapid development, easy maintenance in the laboratory, large number of offspring, and access to experimental manipulation [6]. As the use of fish embryos is considered a refinement, if not replacement of animal experiments [7, 3R principle] and due to the available knowledge of developmental processes of zebrafish, Nagel [5] has introduced the embryo test with the zebrafish Danio rerio test on teratogenicity $(\operatorname{Dar} \mathrm{T})$ as an alternative to the acute fish toxicity test. The DarT analyses acute toxicity in embryos by screening lethal effects, developmental disorders, and other morphological, sublethal endpoints. Next to animal replacement, studies on embryonal stages offer some advantages compared to adults. Test organisms can be obtained in high numbers and at short breeding time, cultivation is less cost and time consuming, organisms are of small size and require no feeding. In Germany, the DarT has already replaced the acute fish tests for toxicity assessment of waste water effluents [8] but is not yet extended for use in chemical risk assessment [9]. Improvement of knowledge about toxic responses regarding sensitivity, specificity, and novel biomarkers increasing the predictive value for possible long-term effects in the embryonic model system [10] would help to advance DarT also for chemical testing.

One possibility to address these challenges might be the analysis of effects at the molecular level [11]. Genomic studies on early life stages of the zebrafish and the highly advanced sequencing of the zebrafish genome (http://www.sanger.ac.uk/Projects/D_rerio/) has lead to the proposal extending the DarT assay to the MolDarT or "GeneDarT" (gene expression Danio rerio embryo test) [12-15]. 
This approach is based on studying gene expression profiles as additional toxicological endpoints and combines both early effect diagnosis and mode of action analysis [16].

The present paper aims to extend the DarT assay in terms of a proteome Danio rerio embryo assay ("ProDarT") analysing effects at the proteome and thus functional level in zebrafish embryos. In environmental monitoring, proteomics has been successfully applied to show sensitive and specific toxicity-related responses in the protein profiles of mussels [17]. Until today, only few proteomics approaches on developing zebrafish with toxicological background [1820] have been published. One of the major drawbacks is the high abundance of yolk proteins (Vitellogenins, Vtgs) early in development of oviparous animals, which can mask and reduce the sensitivity for the detection of changes in the cellular protein pattern. Ziv et al. [21] have studied the proteome of zebrafish oocytes, at a time point at which few yolk proteins have been inoculated in the eggs. Other researchers have applied techniques to manually remove the yolk sacs in early embryos [22, 23]. However, these techniques may interfere with the detection of stress-induced responses by the tested compounds and Vtgs could still be identified after manual deyolking [23]. In the present paper, eleutheroembryos (i.e., hatched but not yet free feeding embryos) are applied since a strong decrease in yolk and yolk proteins has been reported [19, 23-25]. As eleutheroembryos have all organs developed, are not surrounded by a chorion, show increased activities of detoxification processes [26] and are free swimming, toxicodynamic, and kinetic, toxicity processes in eleuthero-embryos might be more similar to adults compared to embryos. To contribute to the further advance of using fish embryos as a method for replacement of experiments with adult fish, a twodimensional-gel electrophoresis-(2-DE) based proteomics approach with 5 days old zebrafish eleuthero-embryos was applied in the present study to (i) investigate toxicity-related responses in the embryonic protein profiles, (ii) characterise the potential for sensitive and specific effect assessment, and (iii) look for candidate protein biomarkers reflecting the organism health status at the molecular level.

For this purpose, effects to the eleutheroembryonal proteome caused by low effect concentrations of three model substances, which have been detected in environment and have different mode of action, two pesticides Rotenone and 4,6dinitro-o-cresol (DNOC) and the drug Diclofenac, were studied.

\section{Experimental Procedures}

2.1. Fish Culture, Embryo Collection, and Eleutheroembryo Bioassay. WIK (Wild-type India Kalcutta) zebrafish were obtained from the Tübingen Zebra Fish Stock Centre at the Max Planck Institute for Developmental Biology and cultivated as described in Küster [27]. The eleutheroembryo bioassays were carried out based on the OECD Draft Guideline for testing of chemicals (OECD 2006) with small modifications due to physicochemical characteristics of model substances (see below).
$79 \mathrm{hpf}$ old eleuthero-embryos were incubated for $48 \mathrm{~h}$ in the exposure solutions at static conditions (temperature $27 \pm$ $1^{\circ} \mathrm{C}, 12 \mathrm{~h} \mathrm{light/dark}$ with $30 \mathrm{mmol}$ photons $\mathrm{m}^{2} \mathrm{~s}^{1}$ ).

The model substances were Rotenone (CAS RN 8379-4), 4,6-dinitro-o-cresol (DNOC, CAS RN 534-52-1), and Diclofenac-sodium salt (CAS RN 15307-79-6). All substances were of analytical grade and purchased from Riedel de Haen (Rotenone and DNOC) and MP Biomedicals (Diclofenac), respectively.

To estimate concentration-response relationships, the model substance Rotenone was tested in the concentration range of $0.25 \mathrm{nM}$ to $2.5 \mu \mathrm{M}$, DNOC from 0.05 to $50 \mu \mathrm{M}$, and Diclofenac between 1.4 and $200 \mu \mathrm{M}$ (nominal concentrations). Constant concentrations are assumed during the $48 \mathrm{~h}$ exposure time with applied conditions for Diclofenac as exposure concentrations were demonstrated to be very stable at the above test conditions (U. Krug, pers. communication). Tests with DNOC were done according to OECD guideline, that is, by using adhesive foils and an additional lid to cover the multiwell plates to decrease possible evaporation. The assay for Rotenone was carried out in glass vials (instead of multiwell plates made from polystyrene) to avoid concentration decrease during exposure due to expected sorption because of the log Kow of 4.1 of Rotenone (EpiSuite Vers. 4.0) as recommended by Riedl et al. [28] and Schreiber et al. [29].

Due to the effect concentrations used, it was not possible to check for the stability of the low exposure concentrations with the currently available analytical methods. Because of that, no statements can be made about the real concentrations. As stated by [28] Riedl and Altenburger (2007) "In ISO 14442 (2004), volatile substances are characterized by a Henry's constant of $\mathrm{H} \geq 1 \mathrm{~Pa} \mathrm{~m}^{3} \mathrm{~mol}^{-1}\left(\log \mathrm{K}_{\mathrm{AW}}=\right.$ -3.4), highly volatile substances by $\mathrm{H} \geq 100 \mathrm{~Pa} \mathrm{~m}^{3} \mathrm{~mol}^{-1}$ $\left(\log \mathrm{K}_{\mathrm{AW}}=-1.4\right)$. Loss of exposure concentration due to lipophilicity is expected for hydrophobic compounds with an octanol/water partition coefficient of log KOW > 4 (OECD SERIES ON TESTING AND ASSESSMENT Number 23, 2000)." Only Rotenone and DNOC were seen as critical in terms of their physicochemical characteristics. So, possible losses in the test system were tried to counteract by the use of glass (lipophilic Rotenone, log $\mathrm{K}_{\mathrm{OW}}$ 4.1) and covering (low volatility of DNOC, Henry constant of $1.4 \times$ $10^{-6} \mathrm{~atm} \mathrm{\textrm {m } ^ { 3 }} / \mathrm{mol}$ ) to decrease the loss of substances to the maximum.

The stock solutions for the proteomic experiment were the same as the ones used for the concentration-response relationships. So, although the real concentrations are not known, the concentrations related to the effect level are similar. After exposure, all eleuthero-embryos were analysed for lethal and sublethal effects by inverse microscopy (50x magnification, Olympus IX70-S8F, Hamburg, Germany). Coagulation, absent blood circulation and absent heartbeat are considered as lethal toxicological endpoints and were used to estimate concentration-response relationships using a logistic model $(y=100+(-100) /(1+(x / x 0)$ p $)$, with $x$ being the concentration in $\%(\mathrm{v} / \mathrm{v}), x 0$ the median effect $\left(\mathrm{EC}_{50}\right)$ and $p$ as the slope) (ORIGIN software, version 6.0, Friedrichsdorf, Germany). 
The estimated $\mathrm{EC}_{10}$ concentrations of these concentration-response relationships were used as the exposure concentration in the following proteome analysis $\left(\mathrm{EC}_{10}\right.$, Rotenone $=0.05 \mu \mathrm{M} ; \mathrm{EC}_{10}$, DNOC $=2.80 \mu \mathrm{M} ; \mathrm{EC}_{10}$, Diclofenac $\left.=12.60 \mu \mathrm{M}\right)$. For the proteomics experiments, $79 \mathrm{hpf}$ old eleutheroembryos were collectively exposed for $48 \mathrm{~h}$ in $200 \mathrm{~mL}$ glass beakers with a density of one organism per $2 \mathrm{~mL}$ exposure solution. In the control experiments, 45 individuals were incubated in $90 \mathrm{~mL}$ of ISOwater (ISO 7346-3). The exposure to the model substances was done with 50 individuals in $100 \mathrm{~mL}$ each. After exposure, the eleuthero-embryos, which did show visible effects were discarded and the left over intact organisms (at least 40 per replicate) were pooled in $2 \mathrm{~mL}$ reaction tubes and the samples were washed four times with $1 \mathrm{~mL}$ of aqua dest. Finally, the embryos were shock frozen in liquid nitrogen and stored at $-80^{\circ} \mathrm{C}$ until analysis.

2.2. Two-Dimensional Gel Electrophoresis. The 2-DE sample preparation was done according to Gündel et al. [19], where proteins were extracted using $0.25 \mathrm{~mL}$ lysis buffer (8 M Urea, 2\% CHAPS, $0.5 \%$ v/v IPGBuffer 47 linear (GE Healthcare, Uppsala, Sweden) and 1\% protease inhibitor cocktail (SIGMA, Taufkirchen, Germany) for each sample (40 pooled embryos). The subsequent 2DE was carried out according to Görg et al. [30]. The isoelectric focusing (IEF) was performed using the Ettan IPGphor (GE Healthcare) and $18 \mathrm{~cm}$ linear, pH 47 immobiline dry strips (GE Healthcare). Rehydration was carried out at room temperature overnight with $400 \mu \mathrm{L}$ rehydration solution per dry strip (DeStreak solution (GE Healthcare), 0.5\% v/v IPGBuffer 4-7 linear (GE Healthcare)). Fifty micrograms of protein were subjected to IEF via cup loading on the cathode and the focussing was performed under following conditions: $150 \mathrm{~V}, 2 \mathrm{~h} ; 300 \mathrm{~V}, 2 \mathrm{~h}$; $600 \mathrm{~V}, 2 \mathrm{~h} ; 8000 \mathrm{~V}$ gradient, $0.5 \mathrm{~h} ; 8000 \mathrm{~V}, 11 \mathrm{~h}$; all steps at $20^{\circ} \mathrm{C}$. After IEF, the immobiline dry strips were equilibrated at room temperature according to Gündel et al. [19]. For the polyacrylamide gel electrophoresis (SDS-Page), as the second dimension, the IPG strips were sealed on the top of $1 \mathrm{~mm}$ thick $14 \%$ polyacrylamide gels (Ettan DALT 12, GE Healthcare). Vertical electrophoresis was carried out overnight $(18 \mathrm{~h})$ at $12^{\circ} \mathrm{C}$ and about $1 \mathrm{~W} /$ gel. The gels were silver stained according to Heukeshoven and Dernick [31] and Yan et al. [32] and digitalized at a resolution of $200 \mathrm{dpi}$ using the image scanner (GE Healthcare, Uppsala, Sweden). Subsequently, they were air dried at room temperature between two cellophane sheets (BioRad, Munich, Germany).

2.3. Image Analysis and Statistics. Densitometric image analysis for the 2DE gels was performed with the software package Delta 2D (Version 3.4, DECODON GmbH, Germany). The $100 \%$ matching strategy was chosen for spot detection. A "fusion" gel of the experiment was created after gel matching of all replicate 2D-gels and all proteins were detected and edited on this virtual "fusion" gel. Subsequently, the detected spot pattern of this fusion gel was transferred to all other gels in the experiment. This method ensures the same spot detection pattern on each gel in one experiment. The amount of protein present in a single spot was described as the spot volume, that is, the area of the spot multiplied by the pixel density. Individual spot volumes were normalised to the total protein amount (e.g., all protein spots added up together) detected within each gel and the amount of each spot was therefore expressed as a relative volume. All proteome analyses were run in triplicates. Due to the inherent semiquantitative silver staining method, the $10 \%$ largest protein spots were excluded from the normalisation set.

Multivariate pattern and univariate spot-to-spotmethods were applied for statistical analysis. Principal component analysis (PCA), including all detected proteins in one experiment, was performed with the software package Jmp (Version 7.0, Cary, USA) to compare protein patterns on the gels. Univariate spot-to-spot analysis was performed using a Student's $t$-test. Hereby, only spots were considered as up- or downregulated proteins, which showed an at least twofold difference in abundance compared to controls and which were significantly different from controls with a $P<.05$ or $<.01$ (highly significant).

2.4. Trypsin Digestion and Identification of Proteins. Proteins of interest were excised from the stained gels. Following silver removal, the spots were subjected to in-gel trypsin digestion as previously described in Benndorf et al. [33] Peptides were reconstituted in $0.1 \%$ formic acid, injected by an autosampler and were concentrated on a trapping column (nanoAcquity UPLC column, C18, $180 \mu \mathrm{m} \times 2 \mathrm{~cm}$, $5 \mu \mathrm{m}$, Waters, Eschborn, Germany) with water containing $0.1 \%$ formic acid at flow rates of $15 \mu \mathrm{L} / \mathrm{min}$. After $4 \mathrm{~min}$, the peptides were eluted onto the separation column (nanoAcquity UPLC column, C18, $75 \mu \mathrm{m} \times 250 \mathrm{~mm}, 1.7 \mu \mathrm{m}$, Waters, Eschborn, Germany). Chromatography was performed by using $0.1 \%$ formic acid in solvents A ( $100 \%$ water) and B (100\% acetonitrile), with peptides eluted over $30 \mathrm{~min}$ with a $8 \%-40 \%$ solvent B gradient using a nano-HPLC system (nanoAcquity, Waters) coupled to an LTQ-Orbitrap mass spectrometer (Thermo Fisher Scientific). Continuous scanning of eluted peptide ions was carried out between 150$2000 \mathrm{~m} / \mathrm{z}$, automatically switching to MS/MS CID mode on ions exceeding an intensity of 2000. Raw MS/MS spectra were converted to mgf-files using the ProteomDiscoverer 1.0 (Thermo Fisher Scientific). MS data were submitted to the online Mascot (http://www.matrixscience.com, may 2009) and searched against Danio rerio (Taxonomy ID: 7955) in the National Centre for Biotechnology Information nucleotide database (NCBInr, may 2009; 70,034 protein entries) tolerating up to two tryptic missed cleavages, a mass tolerance of $10 \mathrm{ppm}$ for precursor ions, $0.5 \mathrm{Da}$ for MS/MS product ions allowing for methionine oxidation (dynamic modification) and cysteine carbamido methylation (static modification). For the Mascot threshold, a probability score of $5 \%$ was applied (significance threshold: $P \leq .05$ ). Hereby, the cutoff score value for accepting individual MS/MS spectra was set to 0 to ensure high-sequence coverage. The identified proteins were characterised via the Swiss-Prot and TrEMBL (www.expasy.org/sprot) databases. All molecular weights (MWs) were calculated by the online PROTPARAM tool (www.expasy.org/tools/protparam.html). 


\section{Results}

3.1. Optimisation of 2-DE Method Concerning Eleutheroembryo Age. The high abundance and high number of yolk vitellogenin (Vtgs) derivatives in protein samples of developing oviparous organisms, like the zebrafish, is a major drawback when lower abundant proteins are to be studied. The known reduction of yolk-to-cell mass during development $[19,23]$ was the basis to address this drawback in the present study. Five days postfertilisation (120 hpf), zebrafish have developed to eleuthero-embryo stages with a strongly reduced yolk, developed mouth and are able to start external feeding. Several authors have shown that at that time of development the zebrafish proteome is not dominated by Vtgs anymore [19, 23, 25]. However, at $120 \mathrm{hpf}$, still some Vtg fragments could be identified in the protein samples as is shown in Supplementary Material available at doi:10.1155/2010/630134 (SM, Table 1) and it can be concluded that yolk utilisation is still not at an end at the fifth day of development. But seven days after fertilisation eleuthero-embryos starve when not fed.

Preceding the toxicoproteomics studies, the optimal sampling time point of eleuthero-embryos combining both, a low number of yolk proteins in the protein samples and the avoidance of starvation stress, had to be found. To characterise the abundance of yolk proteins in the larval proteome, samples deriving from eleuthero-embryos at three different time points (120 hpf, $122.5 \mathrm{hpf}$ and $127 \mathrm{hpf}$ ) were studied (Figure 1). To avoid starvation, no samples from eleuthero-embryos older than $127 \mathrm{hpf}$ were characterised. Although most proteins in the three protein samples show constant abundance at the different measured time points, at least two areas on the gels presented in Figures 1(a)1(c) were quite variable. A strong decrease of the number and amount of the detected proteins in these areas was observed. In previous studies, a couple of proteins of these areas were identified as Vtg derivatives [19]. As the number and abundance of these $\mathrm{Vtg}$ proteins have strongly reduced in samples from $127 \mathrm{hpf}$ old eleuthero-embryos (Figure 1(c)), eleuthero-embryos were sampled at this age/time point for all the following proteomic analyses.

\subsection{Effects of DNOC, Rotenone and Diclofenac on Treated} Eleutheroembryos at Phenotypic Level. The choice of relevant concentrations for the toxicoproteomics experiments with the three tested chemicals was based on the previous characterisation of effects at higher levels of biological organisation (morphological, physiological effects) in the eleutheroembryos. Effect detection in eleuthero-embryos was done similar to the DarT [5] in terms of test regime, exposure time and toxic endpoints. The 48-hour-long exposure in the toxicant solutions started at around $79 \mathrm{hpf}$ when most of the eleuthero-embryos did hatch.

All three substances caused concentration-dependent lethal effects in the organisms. Concentration-effect relationships based on lethal endpoints are shown in Figure 2. The potency of Rotenone $\left(\mathrm{EC}_{50}=0.068 \pm 0.00 \mu \mathrm{M}\right)$ was strongest compared to DNOC $\left(\mathrm{EC}_{50}=3.0 \pm 0.05 \mu \mathrm{M}\right)$ and Diclofenac $\left(\mathrm{EC}_{50}=23 \pm 1.08 \mu \mathrm{M}\right)$. The slopes obtained for the modelled

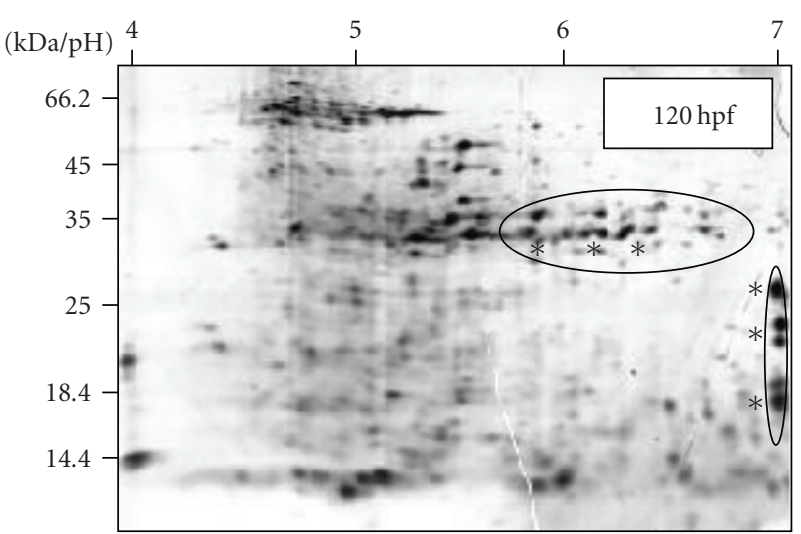

(a)

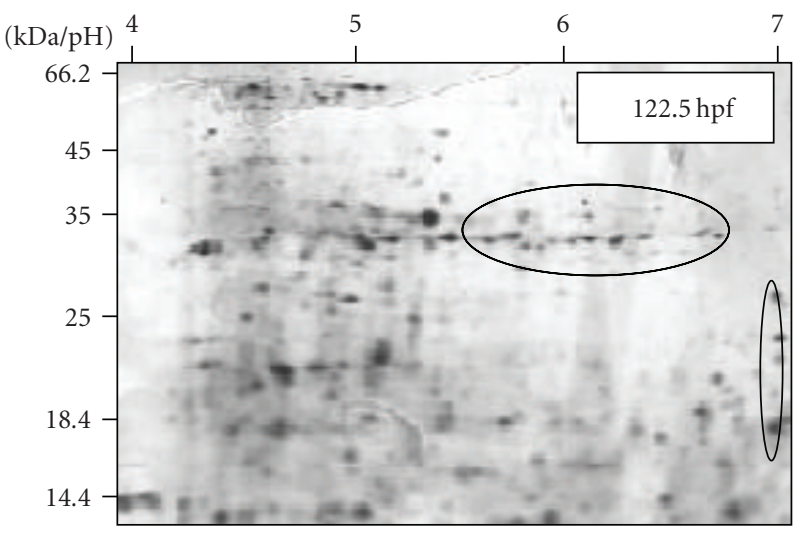

(b)

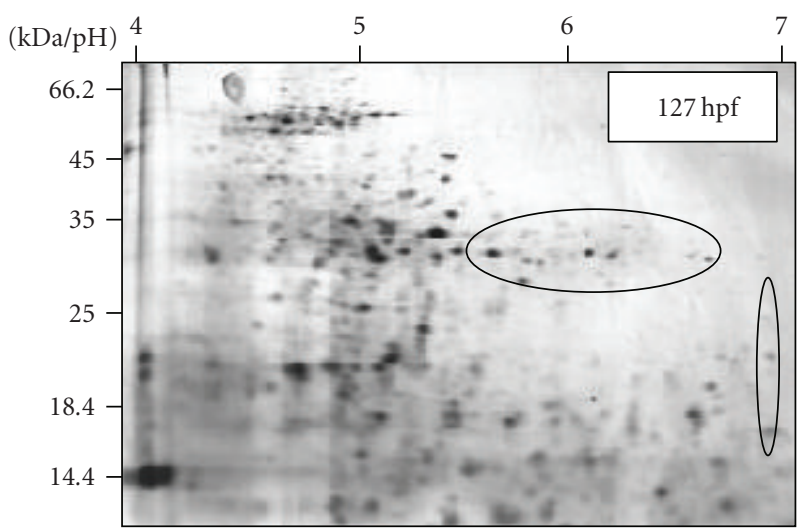

(c)

FIGURE 1: Changes in proteome patterns of eleuthero-embryos at three different time points (a) at $120 \mathrm{hpf}$, (b) at $122.5 \mathrm{hpf}$ and (c) at 127 hpf. Areas with most obvious changes are encircled. Number and abundance of proteins in these areas clearly decrease over time. Proteins identified as vitellogenin derivatives are labelled by asterisks $(*)$.

concentration-effect relationships for Rotenone $(8.75 \pm 2.25)$ and DNOC $(12 \pm 1.80)$ were quite steep and exceeded the one estimated for Diclofenac $(4.75 \pm 1.65)$ exposure in eleutheroembryos. Rotenone and DNOC solely caused coagulation of the organisms, whereas diverse effects in the eleutheroembryos were detected after exposure to Diclofenac. These 


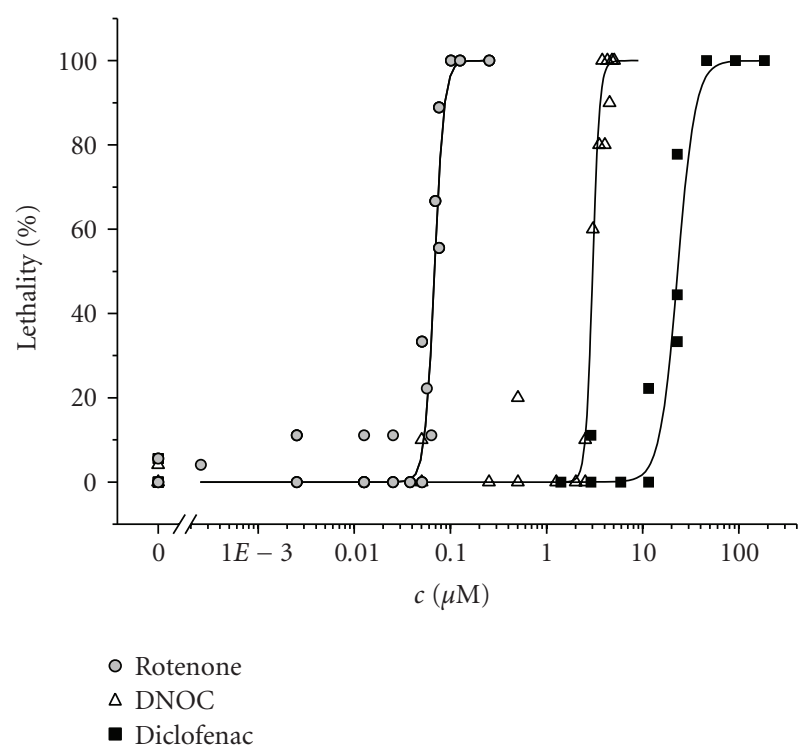

FIGURE 2: Microscopically visible lethal effects of Rotenone, DNOC and Diclofenac to eleuthero-embryos studied after $48 \mathrm{~h}$ exposure. Concentration-effect relationships based on a logistic model are shown. Parameter estimates were as follows: Rotenone: $\mathrm{EC}_{50}[\mu \mathrm{M}]=0.068 \pm 0.00, p=8.750 \pm 2.25$, DNOC: $\mathrm{EC}_{50}[\mu \mathrm{M}]=$ $3.007 \pm 0.05, p=12.311 \pm 1.80$, Diclofenac: $\mathrm{EC}_{50}[\mu \mathrm{M}]=23.076 \pm$ $1.08, p=4.746 \pm 1.65$.

effects included coagulation and lethal impairments in the cardiovascular system but also, to a minor extent, oedema in heart and yolk region or malformations of the backbone.

\subsection{Toxicoproteomics with Zebrafish Eleutheroembryos Using} the Three Toxicants Rotenone, DNOC, and Diclofenac. Rotenone, DNOC and Diclofenac were selected as model substances with different modes of action to study the potential of proteomics for sensitive and specific effect detection. Although they have different molecular toxicity targets, both, Rotenone and DNOC, affect the respiratory chain and were chosen because of their action in an important primary metabolic pathway. The insecticide Rotenone binds, as a primary toxicity target, to the PSST-subunit of complex 1 of the electron chain and inhibits the oxidative phosphorylation [34]. The insecticide and herbicide DNOC acts as a decoupler of the mitochondrial oxidative phosphorylation by decoupling of the electron transport process from ATP synthesis [35]. The pharmaceutical Diclofenac, as an antiinflammatory drug, inhibits the cyclooxygenases COX1 and COX2 [36] and was chosen as a toxicant affecting a secondary biochemical pathway by inhibiting the prostaglandin synthesis.

For all three substances, the modelled low-dose $\mathrm{EC}_{10}$ concentrations were selected for the proteome studies $\left(\mathrm{EC}_{10}\right.$ Rotenone $=0.05 \mu \mathrm{M}, \mathrm{EC}_{10 \mathrm{DNOC}}=2.80 \mu \mathrm{M}$, $\left.\mathrm{EC}_{10 \text { Diclofenac }}=12.60 \mu \mathrm{M}\right)$. To avoid interpretation problems due to aggregating effects at the protein level for affected and nonaffected embryos, only those exposed eleutheroembryos were included in the 2DE experiments that did not show physiological or morphological effects. This procedure should allow the detection of stress induced changes at the molecular level prior the occurrence of microscopically visible effects.

In Figure 3, the typical proteome pattern from control eleuthero-embryos (a) and eleuthero-embryos treated with the $\mathrm{EC}_{10}$ concentrations of Rotenone (b), DNOC (c) and Diclofenac (d) are depicted. Clear differences between the samples and controls are indicated by encircled areas. Two statistical approaches, based on univariate and multivariate analyses tools were applied for the detection of toxicity related changes in the eleuthero-embryo proteome [37].

3.3.1. Principal Component Analysis (PCA). It was performed to analyse the whole proteome pattern of exposed and nonexposed organisms. The received PCA scores for the tested toxicants are shown in Figure 4. The PCA distinguished between control and treatment groups for all three substances.

For all chemicals, the first component (PC1) provided separation between the control and treatment groups (Figures $4(\mathrm{a})-4(\mathrm{c}))$. PC2 and PC3, in contrast, did not contribute information to distinguish between control- and exposureprotein patterns but accounted for variances within the replicates. The percentage contributions for PC1, PC2, and PC3 for each toxicant are shown in Figure 4.

3.3.2. Univariate Spot-to-Spot Analysis. It was performed as a way of analysing the 2-DE experiments to obtain detailed information about single proteins changed in expression or abundance after treatment. Results from univariate analysis are shown in Figure 5 and Table 1.

Overall, Rotenone $\left(\mathrm{EC}_{10}\right)$ caused the highest percentage of significantly changed proteins $(24.1 \%)$, followed by DNOC $\left(\mathrm{EC}_{10}\right)$ with $10.8 \%$ and by Diclofenac $\left(\mathrm{EC}_{10}\right)$ with $6.8 \%$. This order is not changed if only the high-significant changed proteins $(P<.01)$ are considered (indicated in Figure 5 and Table 1). The results from univariate spot-tospot analysis mirror the results from the multivariate analysis showing a sharp separation between control and treatment protein pattern for Rotenone, less clear separation of the treatment conditions for DNOC and low difference between control and treatment groups for Diclofenac (Figure 4). The spot IDs, relative volumes, standard distributions and Student's $t$-test results for all differentially expressed proteins obtained from treatment with the single substances are shown on 2-DE gels and tables in the Supplemental Material (Figures SM1 and SM2, Tables 3-5).

3.4. Comparison of Results from Toxicoproteomics Experiments with Rotenone, DNOC, and Diclofenac. Changes in the eleuthero-embryo proteome pattern from all treatment conditions (Rotenone, DNOC and Diclofenac) were compared to enable the differentiation between unspecific from model substance specific reactions. Comparison was realised on pattern-(Figure 6(a)) and individual-protein level (Figures 6(b) and 6(c)). 


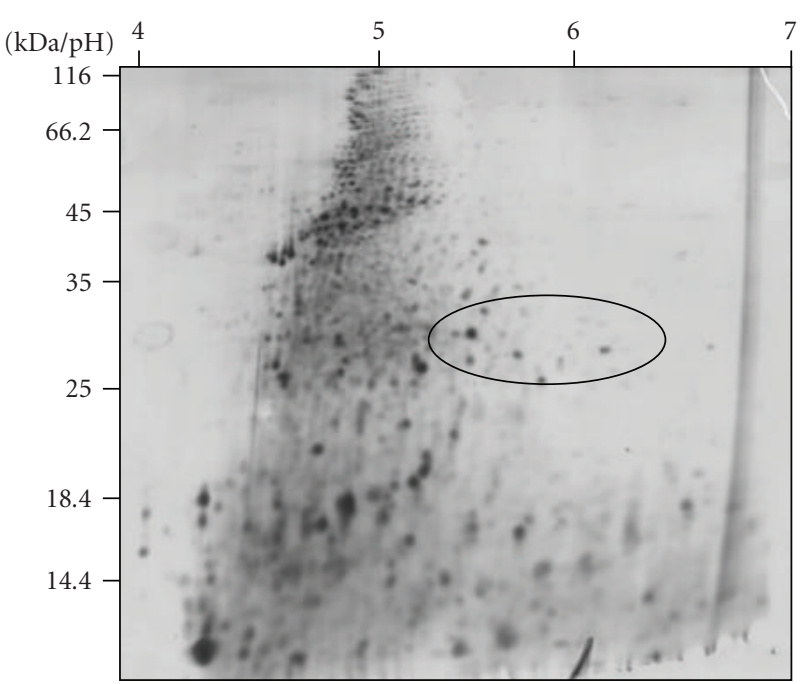

(a)

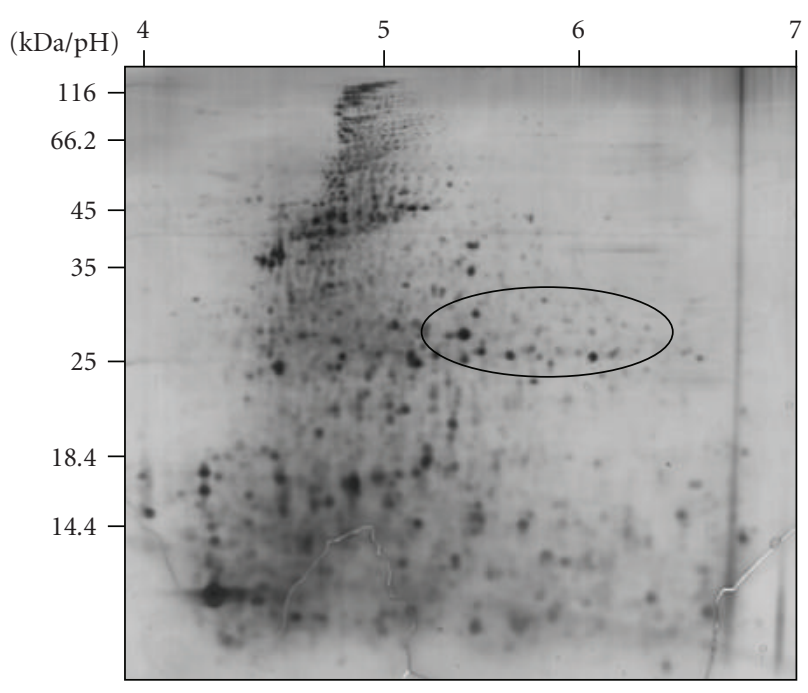

(c)

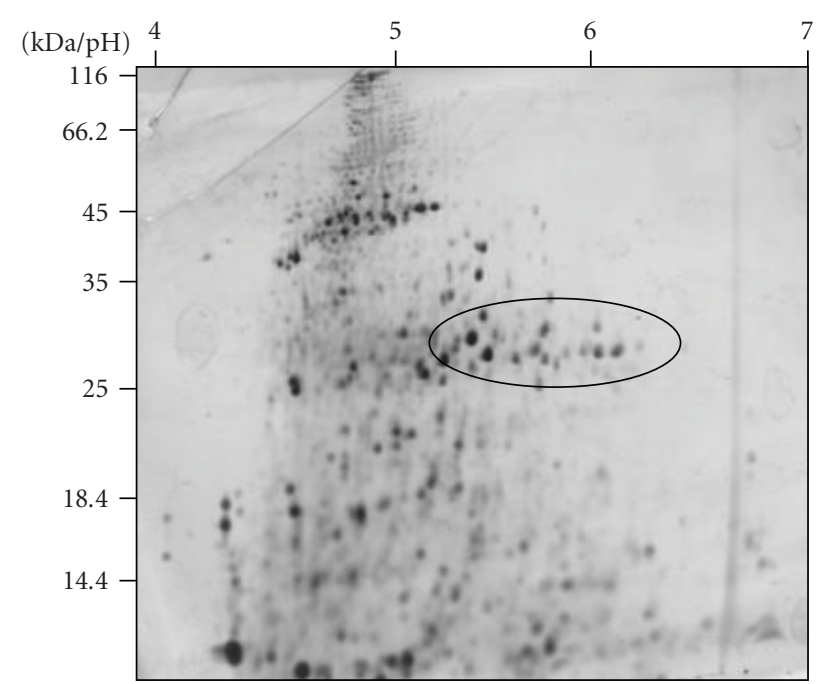

(b)

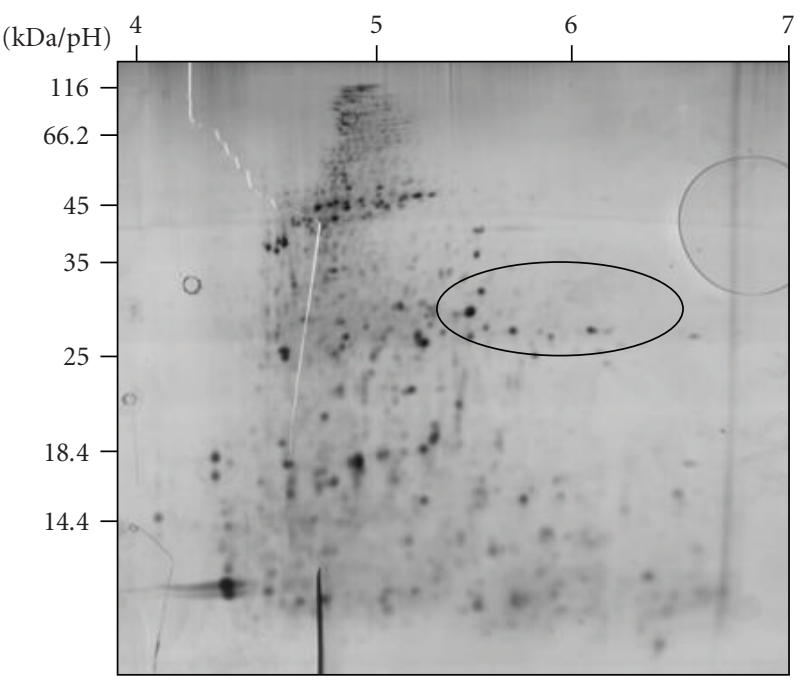

(d)

FIGURE 3: 2-DE gels from proteomics experiments: (a) control conditions, (b) $\mathrm{EC}_{10}$ treatment with Rotenone, (c), EC 10 treatment with DNOC and (d) $\mathrm{EC}_{10}$ treatment with Diclofenac. All protein samples were separated under the same 2-DE conditions: Immobiline strips pH 4-7 in the first and 14\% PAA gels in the second dimension.

All obtained control protein patterns could be clearly distinguished from treatment situations by principal component 1 (Figure 6(a)) whereas PC2 separated controls belonging to different experiments. $\mathrm{PC} 1$ also provided a separation between proteome patterns of Rotenone treated eleuthero-embryos and the other treatments. PC3 sorted the protein patterns according to all three different treatment groups (Figure 6(a)). These results were confirmed considering the comparison at the individual protein level, which is demonstrated in the Venn diagram in Figure 6(b). So, each model substance caused its own set of differentially expressed proteins.

However, next to substance specific changed proteins also proteins were detected, which showed changed expression levels independent of substance identity. These are indicated on the 2DE gel in Figure 6(c) and in the Supplemental Material (SM, Table 2). Nine proteins could be detected, which simultaneously changed expression levels after Rotenone, DNOC, and Diclofenac treatment. These might be a base set for the development of general stress biomarkers for the indication of exposure. This was confirmed by first identification results of those proteins that had been associated with stress by Monsinjon and Knigge [37] (Table 2).

\section{Discussion}

Improvement of knowledge about toxic responses and regarding information on sensitivity and specificity of effect assessment might contribute to the advance of the zebrafish embryo test for testing of chemicals as animal replacement 


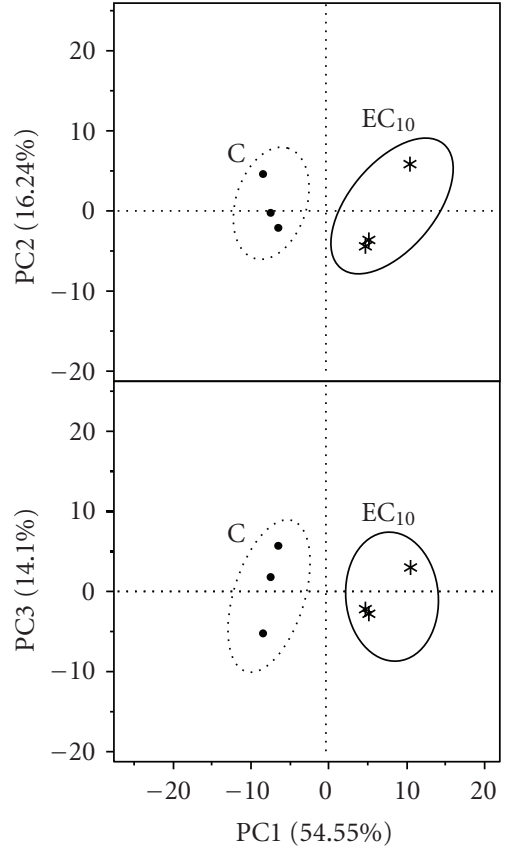

(a)

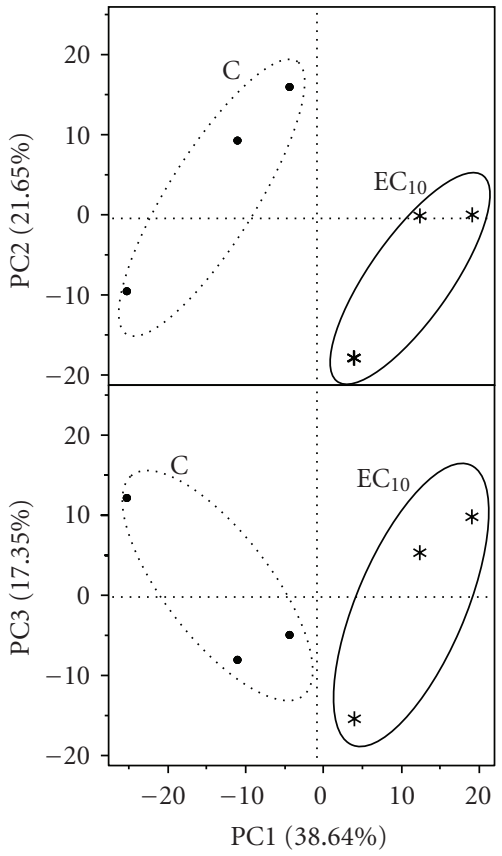

(b)

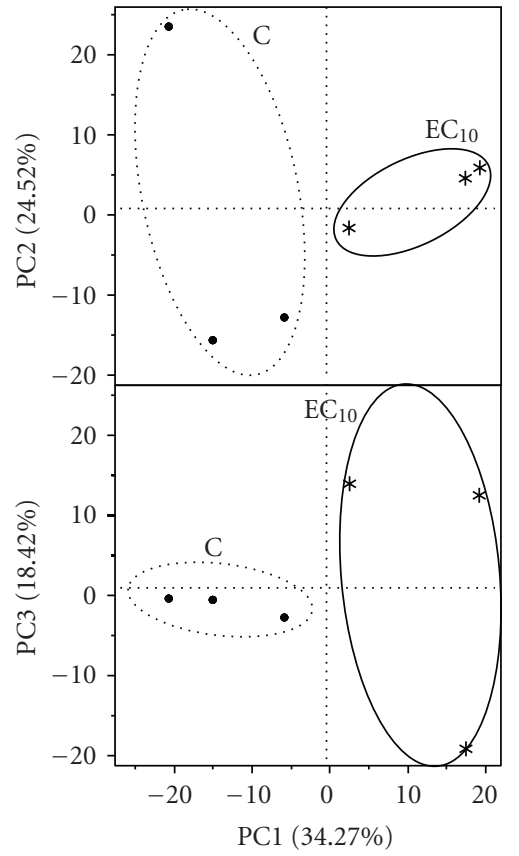

(c)

FIGURE 4: Principal component analysis scores (PC1, PC2, and PC3) for protein pattern assessment of control and treated eleutheroembryos with (a) Rotenone, (b) DNOC, and (c) Diclofenac. Control groups are indicated with c. Three independent replicates were performed for all treatment groups $\left(\mathrm{EC}_{10}\right.$ treatment with either Rotenone, DNOC, or Diclofenac).

TABLE 1: Summary of results from spot-to-spot analysis for all performed toxicoproteomics experiments: Diclofenac (EC 10 ), Rotenone $\left(\mathrm{EC}_{10}\right)$ and DNOC $\left(\mathrm{EC}_{10}\right)$. Numbers and percentage (in relation to total protein number on the gel) of significantly $(P<.05)$ and highlysignificantly $(P<.01)$ at least twofold changed proteins are indicated in the table. Data are sorted for up-regulated (oe, ratio sample/control $>2$ ) and down-regulated (rp, ratio sample/control <2) proteins. In addition, the sum or percentage of all changed proteins for each condition is shown (rp and oe).

\begin{tabular}{|c|c|c|c|c|c|c|c|c|}
\hline Toxi Compound & $\begin{array}{l}\text { Total number of } \\
\text { Proteins } \\
\text { detected on the } \\
\text { gels }\end{array}$ & $P$ value & $\begin{array}{l}\text { rp [number } \\
\text { of proteins] }\end{array}$ & $\begin{array}{l}\mathrm{rp} \\
{[\%]}\end{array}$ & $\begin{array}{l}\text { oe [number } \\
\text { of proteins] }\end{array}$ & $\begin{array}{c}\text { oe } \\
{[\%]}\end{array}$ & $\begin{array}{l}\text { rp and oe [number } \\
\text { of proteins] }\end{array}$ & $\begin{array}{c}\text { rp and oe } \\
{[\%]}\end{array}$ \\
\hline \multirow{2}{*}{ Diclofenac } & 814 & 0.05 & 14 & 1.7 & 41 & 5.0 & 55 & 6.8 \\
\hline & 814 & 0.01 & 4 & 0.5 & 15 & 1.8 & 19 & 2.3 \\
\hline \multirow{2}{*}{ Rotenone } & 860 & 0.05 & 91 & 10.6 & 116 & 13.5 & 207 & 24.1 \\
\hline & 860 & 0.01 & 39 & 4.5 & 68 & 8.4 & 107 & 12.9 \\
\hline \multirow{2}{*}{ DNOC } & 703 & 0.05 & 20 & 2.8 & 56 & 8.0 & 76 & 10.8 \\
\hline & 703 & 0.01 & 5 & 0.7 & 17 & 2.4 & 22 & 3.1 \\
\hline
\end{tabular}

method for regulatory purposes. The aim of the present paper was to characterise the potential of proteomics with zebrafish eleuthero-embryos for sensitive and specific effect assessment of chemical exposure, which, to our knowledge, has not been studied so far. Hereby, the main questions to be answered were whether toxicity related responses can be detected at low-dose ranges in the proteome profiles of treated eleuthero-embryos, whether exposure with different model substances can be discriminated at the proteome level and whether possible candidate protein biomarkers for predictive effect diagnosis might be proposed. Therefore, proteomics was established for zebrafish eleuthero-embryos and proteomic analyses were performed with three different compounds, including two insecticides, affecting primary metabolic pathways (oxidative phosphorylation), Rotenone and DNOC [38, 39], and the pharmaceutical Diclofenac, with an anti-inflammatory mode of action [36].

The results will be discussed in two parts. Firstly, methodological aspects including eleuthero-embryo age and the applied model substances are discussed. In the second part, the discussion is related to the results of the proteomic experiments. 
TABLE 2: Summary of positive identification of protein spots changed in expression after exposure to $\mathrm{EC}_{10}$ concentrations of Rotenone (R), DNOC (D) and Diclofenac (Dic) to zebrafish eleuthero-embryos.

\begin{tabular}{|c|c|c|c|c|c|c|c|c|c|c|}
\hline Spot & $\begin{array}{l}\text { Mascot } \\
\text { Score }\end{array}$ & Protein Name & $\begin{array}{l}\text { UniProtKB } \\
\text { Accession }\end{array}$ & $\begin{array}{l}\text { Peptides } \\
\text { assigned }\end{array}$ & $\begin{array}{c}\text { Sequence } \\
\text { coverage } \\
{[\%]}\end{array}$ & $\begin{array}{c}\mathrm{MW}_{\mathrm{obs} / \mathrm{cal}} \\
{[\mathrm{kDa}]}\end{array}$ & $\mathrm{pI}_{\mathrm{obs} / \mathrm{cal}}$ & $\begin{array}{c}\text { Ratio } \\
\text { Rotenone }\end{array}$ & $\begin{array}{l}\text { Ratio } \\
\text { DNOC }\end{array}$ & $\begin{array}{c}\text { Ratio } \\
\text { Diclofenac }\end{array}$ \\
\hline Dic11o, D, R & 430.29 & vitellogenin 1 & Q1LWN2 & 12 & 8.7 & $30.0 / 128.0$ & $5.6 / 8.68$ & 13.6 & 4.1 & 2.4 \\
\hline Dic14o, D, R & 94.0 & $\begin{array}{l}\text { LOC553473 } \\
(\beta \text {-crystallin })\end{array}$ & Q502C7 & 5 & 10.8 & $24.5 / 27.6$ & $5.9 / 7.67$ & 47.3 & 3.1 & 3.0 \\
\hline Dic27o, D, R & 197.79 & $\begin{array}{l}\text { actin, alpha, } \\
\text { cardiac muscle 1a }\end{array}$ & Q6IQR3 & 10 & 23.1 & $45.0 / 42.0$ & $5.6 / 5.22$ & 3.3 & 3.6 & 2.3 \\
\hline Dic47o, D, R & 644.34 & tubulin, beta $2 c$ & Q6P5M9 & 25 & 25.8 & $44.0 / 49.8$ & $5.5 / 4.79$ & 40.6 & 12 & 26.5 \\
\hline Dic64r, D, R & 321.38 & $\begin{array}{l}\text { myosin, light } \\
\text { polypeptide } 2\end{array}$ & O93409 & 14 & 50.3 & $17.0 / 18.9$ & $4.7 / 4.39$ & 0.4 & 0.5 & 0.5 \\
\hline
\end{tabular}

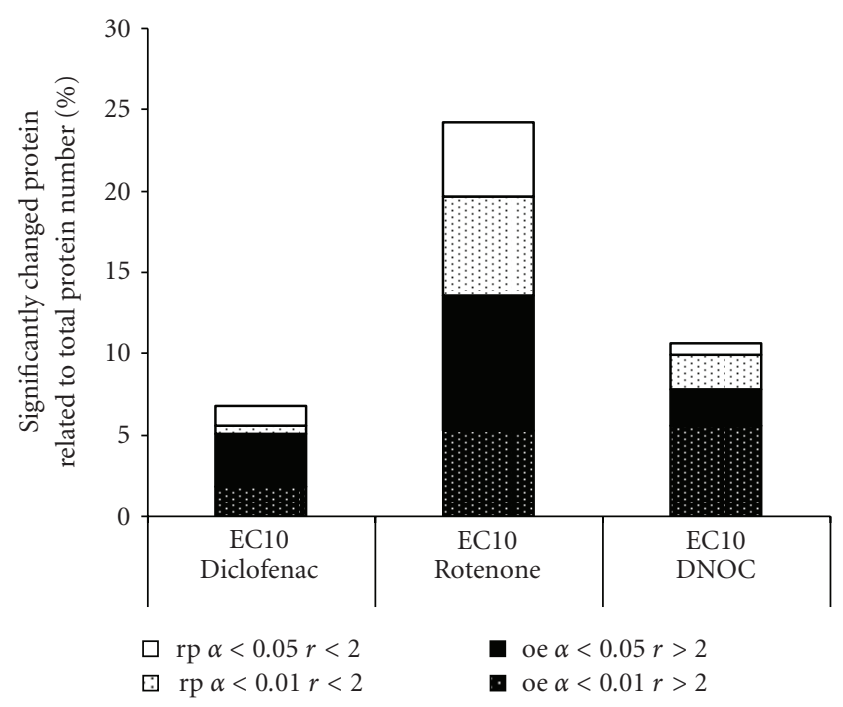

Figure 5: Summary of results from spot-to-spot analysis of proteomics experiments with Diclofenac (Dic), Rotenone(R), and DNOC (D). For all tested concentrations the percentages of protein spots, related to all detected protein spots in the 2-DE experiment, are depicted that show significant $(P<.05)$ or highly significant changes $(P<.01)$ and a minimum of twofold changed expression levels compared to controls. Proteins showing an at least twofold increase in abundance compared to control $(r<2)$ are considered as upregulated (oe), all proteins showing an at least twofold decrease in abundance compared to controls are considered as downregulated (rp).

\subsection{Methodological Aspects}

4.1.1. Eleutheroembryo Age. In contrast to adult animals, proteome analysis of developing organisms addresses a biological system that is highly variable in terms of physiological, morphological, and other parameters over time, which is very likely to be mirrored at the molecular level. Hence, the exact sampling point of eleuthero-embryos for the proteomics studies is of concern. Eleuthero-embryos were sampled at $127 \mathrm{hpf}$ for the proteome analyses for two reasons. On the one hand, the observed shift of the $2 \mathrm{DE}$ protein patterns from yolk proteins towards cellular proteins during embryonal development $[19,23]$ is nearly completed at this developmental stage and Vtg rich areas on the gels are not predominant anymore. On the other hand, $127 \mathrm{hpf}$ old eleuthero-embryos are vital and do not show signs of starvation, which could be assumed if yolk is nearly utilised and no external feeding of the organisms would take place. To our knowledge, the point of time of complete yolk consumption in Danio rerio has not been investigated so far. However, yolk utilisation may strongly depend on many parameters including movements of the eleutheroembryos, temperature or light conditions. These parameters might vary slightly for each biological sample deriving from eleuthero-embryos and could lead to differences in the proteome pattern. Hence, for all performed proteomic experiments controls from the same spawning event as the treated samples were included. This is also proposed for any future applications of proteomics with zebrafish eleutheroembryos.

4.1.2. Concentrations Tested. The output of a proteomics experiment strongly depends on the applied model substance concentrations and exposure times and should be interpreted in relation to observed effects at higher biological organisation levels in the analysed organisms. As a shortcoming we have to state that it was not possible to quantify the exact concentrations mainly due to the low concentrations of two of the substances $\left(\mathrm{EC}_{10}\right)$, the volumes used and the respective limits of quantification. In spite of the above, all effects on higher organisation levels like morphological, physiological or behavioural effects are preceded by effects at the molecular level [11]. Proteomics investigations at substance concentrations or exposure times that do not cause any microscopically visible effects in the organisms may lead to the identification of proteins involved in the primary response or adaptation processes after exposure $[17,18,40]$. This could be used for prediction of effects at higher organisation levels [37]. However, without relation to effects at the phenotypic level, the selection of concentrations or exposure times causing detectable relevant effects at the proteome level might be difficult. But the discussion of exposure concentrations in relation to concentration dependent phenotypic effects for the proteomics experimental setup has not been focus of many ecotoxicoproteomics studies so far [17]. The investigation of low-effect concentrations like 


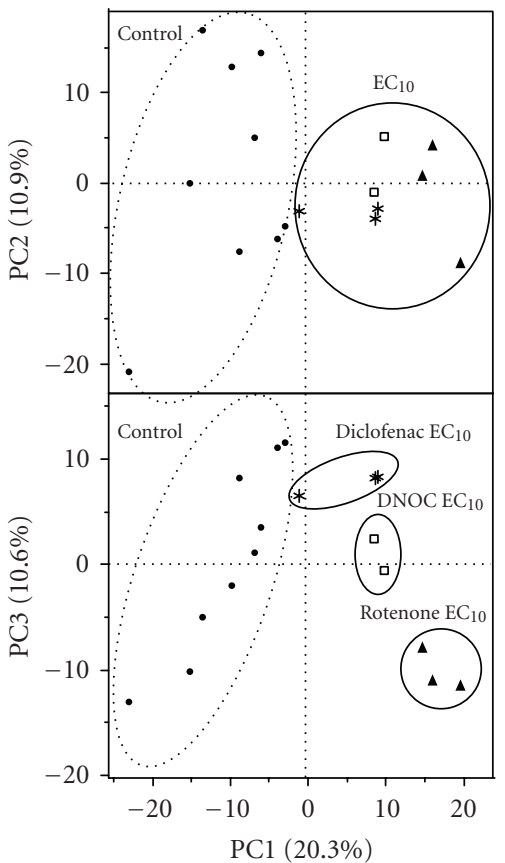

(a)

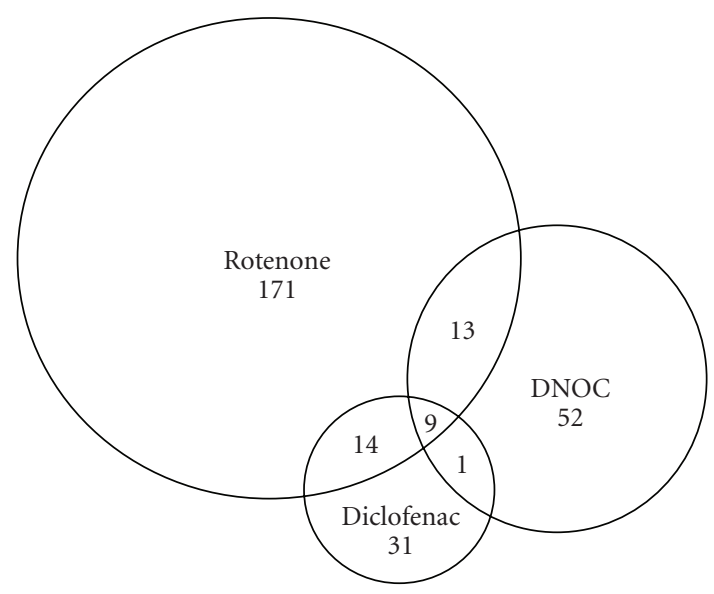

(b)

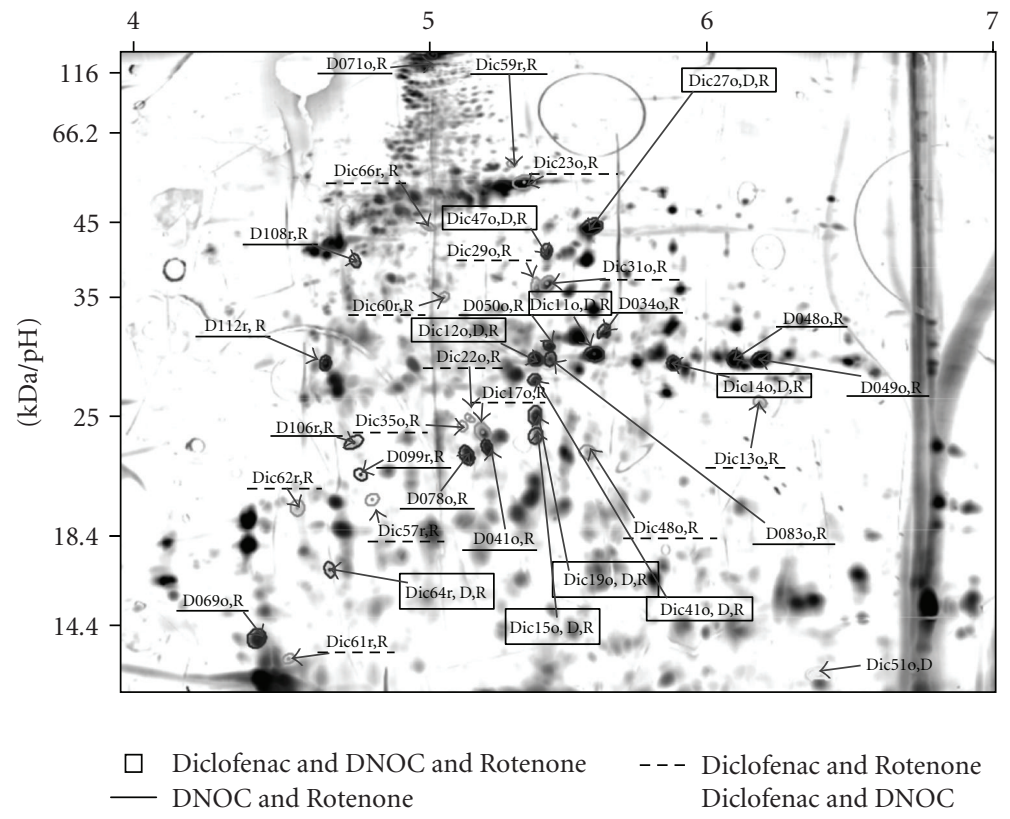

(c)

FIGURE 6: Comparison of results from toxicoproteomics experiments with Rotenone, DNOC, and Diclofenac exposure. (a) PCA scores when all samples are included in PCA analysis. (b) Venn-Diagramm based on results from substance-specific univariate spot-to-spot analysis. Most of the protein spots changed specifically. 9 proteins concurrently changed after Rotenone, DNOC, and Diclofenac treatment. Moreover, 13 proteins simultaneously changed after Rotenone and DNOC treatment, and 14 proteins showed changed expression levels at exposure against Diclofenac or Rotenone. Only one protein was found to be changed in the larval protein samples after DNOC as well as Diclofenac treatment. (c) 2-DE gel from eleutheroembryonal protein samples. All proteins that significantly changed in expression in at least two toxicoproteomics experiments (treatment with either Rotenone, DNOC, or Diclofenac) are labelled: Protein labels of protein spots simultaneously altered in Rotenone, DNOC, and Diclofenac experiments are framed $(\square)$, in Rotenone and DNOC experiments are underlined (-), in Rotenone and Diclofenac experiments are dashed (-), and in DNOC, and Diclofenac experiments are labelled by name only. 
$\mathrm{EC}_{10}$ as done here with a proteomics approach in intact organisms enables both, the testing of a toxicity relevant concentration and the analyses of molecular effects, which precede phenotypic physiological or morphological effects.

\subsection{Proteomics Experiments: Sensitivity and Specificity of Responses}

4.2.1. Sensitivity. One question of the present study was whether toxic stress can be detected in the proteome of treated zebrafish eleuthero-embryos that do not show a microscopically visible damage. By application of multivariate and univariate methods for the analysis of the proteomics data, proteome pattern of control and treated but intact eleuthero-embryos could clearly be distinguished at low sublethal concentrations of Rotenone, DNOC and Diclofenac. It can be concluded that the proteomics approach for all analysed substances lead to detection of a response at the molecular level in eleuthero-embryos not showing microscopically visible lesions. This would confirm the suggested scope of toxicogenomics approaches $[11,37,40]$ to sensitively detect effects at the molecular level prior to the occurrence of effects at the phenotypic level and the definition of marker proteins, which might be used for predictive effect diagnosis [41].

4.2.2. Specificity. The characterisation of the specificity of the detected response to treatments with different substances with the applied proteomics approach was a further major concern in the present study. In terms of specificity, the established DarT assay sometimes has limitations $[6,10]$. The results of the DarT as performed in this study confirm such concerns as less specific reactions were detectable at the phenotypic level after Rotenone, DNOC and Diclofenac treatment. Observed effects caused by the three different substances were quite similar and coagulation was predominant. Early responses at the molecular level are supposed to be more related to substance specific effects [11] that could also give hints to mode of action and mechanisms of toxicity of the tested substances [41]. This is supported by PCA based pattern analyses clearly distinguishing between proteomes of eleuthero-embryos treated with the different model substances. Moreover, each tested substance caused its own specific pattern of changed proteins and hence, its own protein expression signature (PES). The term PES was introduced by Bradley and coworkers $[42,43]$ to define a set of proteins differing between contaminant exposure and control. Shrader et al. [20] demonstrated the applicability for PES to distinguish between different exposure scenarios with endocrine-disruption in zebrafish embryos. By studying mussels from different polluted field sites, Knigge et al. [44] also described a subset of proteins forming a classifier to distinguish between polluted and unpolluted situations. PES can enable the identification of substance specific biomarker patterns, which are considered to provide an overcome of the uncertainties associated with the extraction of single protein markers as described by Knigge et al. [44] and Monsinjon and Knigge [37]. This was also shown in a toxicogenomic study that described specific gene expression profile pattern in zebrafish embryos enabling the discrimination of exposure against 11 model compounds [16] or by a toxicoproteomics study of marine pollutants on mussels [17]. Hence, with our results having identified specific protein patterns for each exposure scenario would support the concept of PES and the idea of extracting information for certain exposure scenarios solely from changed protein patterns without the need to identify single proteins.

The PES of each substance was mainly determined by the number of changed proteins. For all three substances the same effect concentration, which lead to microscopically visible effects in $10 \%$ of the treated organisms $\left(\mathrm{EC}_{10}\right)$, was tested with the toxicoproteomic approach. At the molecular level, however, in terms of the number of differentially expressed proteins, differences in the effect levels could be detected for all three substances. At $\mathrm{EC}_{10}$ concentration, Rotenone caused the change of about $24 \%$ of all detected proteins, DNOC of about $11 \%$ and Diclofenac of about $7 \%$ of all proteins. So, the observed effect level at the molecular level differs from the effect level derived from analysis of visible toxic endpoints at the phenotypic level but, interestingly, correlated well with the determined potencies of the substances. Most detected proteins from whole embryonic fish proteomic studies are likely to belong to high-abundant protein classes such as cellular organisation or metabolic pathways. These have been previously associated with toxic stress [37]. Thus, it might be stated that the number of changed proteins in ecotoxicoproteomics studies of whole organisms might correlate with the stress or decompensation status of the organism.

Analysing the number of changed proteins the effect analysis at the proteome level could give information on how basal the affected metabolic pathways are in contrast to classical toxic endpoints. Rotenone and DNOC have a mode of action in a primary metabolic pathway, the oxidative phosphorylation $[38,39]$. Both substances caused an effect on a higher number of proteins in the proteome compared to Diclofenac with the primary mode of action in a secondary biochemical pathway (inhibition of cyclooxygenases) [36]. Direct impairments in energy metabolism affect many cellular processes and enzymes and are in direct relation to changed rates of biosyntheses, as general protein biosynthesis, all of which uses up ATP. Hence, changes of many proteins in the larval proteome after Rotenone or DNOC treatment may well be considered as plausible. For Rotenone, this was also confirmed by a proteomics study from Jin et al. [45] who identified 110 significantly changed mitochondrial proteins in Rotenone exposed dopameric cell lines. The reversibility of mode of action from Rotenone and DNOC and the multiple other actions described for Rotenone [46-48] might be consulted for explaining the higher number of changed proteins after Rotenone treatment compared to DNOC. Future protein identifications would help to obtain closer insights in mechanisms of toxicity of the tested substances but were not within the scope of this study.

4.2.3. General Stress Markers. Although specific PES were detectable for Rotenone, DNOC and Diclofenac, spot-tospot analyses revealed 9 proteins that showed concurrently 
and significantly changed expression levels after treatment with all substances. Apraiz and co-workers [17] have introduced the term "minimal PES" for the set of generally responding proteins. These proteins seem to respond to a wider variety of toxic stress and might provide an origin for the development of unspecific biomarkers distinguishing between control and exposure scenarios.

Identification results have shown that one of these proteins matched to vitellogenin sequences. Vitellogenins are yolk proteins that serve in embryonic nutrition and which decrease in abundance during development $[19,23]$. An increased abundance of those vitellogenins (Vtg) in exposed eleuthero-embryos might indicate retardation in development of the exposed eleuthero-embryos at the molecular level, which can hardly be followed with microscopy based methods. As the detected Vtg protein is a Vtg fragment, endocrine disrupting processes, which have been also associated with (full-length) Vtg expression [15] are not assumed here.

In addition, three cytoskeleton proteins (myosin, actin, and tubulin) were identified. This is in accordance to other toxicoproteomics studies, which have found cytoskeleton proteins associated with toxic responses [17, 37]. The cytoskeleton has been proposed to be one of the first targets of oxidative stress [49] and Apraiz et al. [17] have extensively discussed the expression change of tubulin, which they found to be part of the minimal PES after exposure of mussels to three different chemicals. Shi et al. [18] also described that cytoskeleton maintenance was predominantly affected in zebrafish larvae after PFOS exposure and Manduzio et al. [50] found altered expression of actins and myosins in mussels as indication for water pollution. Although, there is also criticism about housekeeping proteins to be good marker proteins [37], our results support studies, which have shown that toxic exposure might lead to significant changes in abundance of cytoskeleton proteins. These could serve as markers to monitor the health status of an organism.

$\beta$-crystallin also responded to exposure with all three substances. Crystallins are the dominant structural components of the vertebrate eye lens and alteration in its expression might be connected to disturbed embryonal eye development. A connection of toxic exposure and lens degeneration in fish has been recently published [51] Moreover, Shi et al. [18] have detected a correlation of $\gamma$ crystalline expression and toxic stress in protein profiles of PFOS treated zebrafish larvae.

It can be concluded that the established toxicoproteomics approach with zebrafish eleuthero-embryos enabled the detection of candidate protein markers indicating developmental impairments and toxic stress at the molecular level prior the manifestation of visible lesions. Perceivable next steps will concentrate on assay development such as enzyme assays or Western blots for some of the found protein markers. This enables the analysis of robustness and exposure-time and exposure-concentration dependence of the found protein signals after exposure to chemical stress and to characterise their potential to be stress biomarkers in Danio rerio embryos.

\section{Conclusions}

Proteomics was established for eleuthero-embryos of the zebrafish (Danio rerio). With univariate and multivariate statistical analysis tools, the potential of this approach was confirmed to sensitively detect effects in organisms treated with low toxicant concentrations of the model substances Rotenone, DNOC, and Diclofenac. The different exposure scenarios could be distinguished at the molecular level as each substance caused its own protein expression signature. Moreover, it was shown that proteomic investigations hold the possibility to detect candidate protein markers that might serve as general stress markers indicating the health status of an organism and be usable for early diagnosis of toxic stress. Thus, an extension of DarT to the study of effects at the proteome level (ProDar $\mathrm{T})$ promises to allow a more sensitive, specific and refined toxicity assessment.

\section{Abbreviations}

$\begin{array}{ll}\text { COX: } & \text { Cyclooxygenase } \\ \text { DarT: } & \text { Zebra fish embryo toxicity test } \\ \text { 2DE: } & \text { Two-dimensional gel electrophoresis } \\ \text { DNOC: } & \text { Dinitro-o-cresol } \\ \text { Dpf: } & \text { Days post fertilisation } \\ \text { EC: } & \text { Effect concentration } \\ \text { Hpf: } & \text { Hours post fertilisation } \\ \text { ISO: } & \text { International Standard Organisation } \\ \text { Lv: } & \text { Lipovitellin } \\ \text { MW: } & \text { Molecular weight } \\ \text { oe: } & \text { Up-regulated } \\ \text { PCA: } & \text { Principal component analysis } \\ \text { PES: } & \text { Protein expression signature } \\ \text { ProDarT: } & \text { Toxicoproteomics with embryos of Danio rerio } \\ \text { Pv: } & \text { Phosvitin } \\ \text { rp: } & \text { downregulated } \\ \text { SM: } & \text { Supplementary material } \\ \text { Vtg: } & \text { Vitellogenin }\end{array}$

\section{Acknowledgments}

This paper was financially supported by PROTECTOR: Recycling and upgrading of bone meal for environmentally friendly crop protection and nutrition (EU Contract no: FOOD-CT-2005-514082) and by ProDarT (BMBF, German Ministry for education and research, FKZ0315399). The authors would like to thank Silke Aulhorn for excellent technical assistance and Nico Jehmlich, Michaela Risch, and Jana Seifert of the Department Proteomics at the HelmholtzCentre for Environmental Research (UFZ), Leipzig, Germany for support in MS based protein identification.

\section{References}

[1] OECD 203, "Fish Acute Toxicity Test. OECD guideline for the testing of chemicals," 1992, http://www.oecd.org/ dataoecd/17/20/1948241.pdf.

[2] R. C. Eaton and R. D. Farley, "Spawning cycle and eggproduction of zebrafish, brachi Danio rerio, in laboratory," Copeia, vol. 1, pp. 195-204, 1974. 
[3] L. E. Coverdale, D. Lean, and C. C. Martin, "Not just a fishing trip-environmental genomics using zebrafish," Current Genomics, vol. 5, no. 5, pp. 395-407, 2004.

[4] J. M. Spitsbergen and M. L. Kent, "The state of the art of the zebrafish model for toxicology and toxicologic pathology research-advantages and current limitations," Toxicologic Pathology, vol. 31, pp. 62-87, 2003.

[5] R. Nagel, "DarT: the embryo test with the Zebrafish Danio rerio-a general model in ecotoxicology and toxicology," Altex, vol. 19, pp. 38-47, 2002.

[6] S. Scholz, S. Fischer, U. Gündel, E. Küster, T. Luckenbach, and D. Voelker, "The zebrafish embryo model in environmental risk assessment - applications beyond acute toxicity testing," Environmental Science and Pollution Research, vol. 15, no. 5, pp. 394-404, 2008.

[7] W. M. S. Russell and R. L. Burch, The Principles of Humane Experimental Technique, Methuen, London, UK, 1959.

[8] "Announcement of the amendment of the Wastewater Charges Act on January 18, 2005," Federal Law Gazette, vol. 2005, part 1, no. 5, 2005.

[9] OECD, "Fish Embryo Toxicity (FET) Test. Draft OECD guideline for the testing of chemicals," 2006, http://www.oecd .org/dataoecd/39/59/36817070.pdf.

[10] J. Bachmann, Entwicklung und Erprobung eines TeratogenitätsScreening Testes mit Embryonen des Zebrabärblings Danio rerio, Ph.D. thesis, University of Dresden, Dresden, Germany, 2002, http://deposit.ddb.de/cgi-bin/dokserv?idn=965592936 \&dok_var=d1\&dok_ext=pdf\&filename=965592936.pdf.

[11] W. H. Clements, "Integrating effects of contaminants across levels of biological organization: an overview," Journal of Aquatic Ecosystem Stress and Recovery, vol. 7, no. 2, pp. 113$116,2000$.

[12] A. Liedtke, J. Muncke, K. Rüfenacht, and R. I. L. Eggen, "Molecular multi-effect screening of environmental pollutants using the MolDarT," Environmental Toxicology, vol. 23, no. 1, pp. 59-67, 2007.

[13] J. Muncke, M. Junghans, and R. I. L. Eggen, “Testing estrogenicity of known and novel (xeno-)estrogens in the MolDarT using developing zebrafish (Danio rerio)," Environmental Toxicology, vol. 22, no. 2, pp. 185-193, 2007.

[14] D. Voelker, C. Vess, M. Tillmann et al., "Differential gene expression as a toxicant-sensitive endpoint in zebrafish embryos and larvae," Aquatic Toxicology, vol. 81, no. 4, pp. 355-364, 2007.

[15] J. Muncke and R. I. L. Eggen, "Vitellogenin 1 mRNA as an early molecular biomarker for endocrine disruption in developing zebrafish (Danio rerio)," Environmental Toxicology and Chemistry, vol. 25, no. 10, pp. 2734-2741, 2006.

[16] L. Yang, J. R. Kemadjou, C. Zinsmeister et al., “Transcriptional profiling reveals barcode-like toxicogenomic responses in the zebrafish embryo," Genome Biology, vol. 8, no. 10, Article ID R227, pp. 1-17, 2007.

[17] I. Apraiz, J. Mi, and S. Cristobal, "Identification of proteomic signatures of exposure to marine pollutants in mussels (Mytilus edulis)," Molecular and Cellular Proteomics, vol. 5, no. 7, pp. 1274-1285, 2006.

[18] X. Shi, L. W. Y. Yeung, P. K. S. Lam, R. S. S. Wu, and B. Zhou, "Protein profiles in zebrafish (Danio rerio) embryos exposed to perfluorooctane sulfonate," Toxicological Sciences, vol. 110, no. 2, pp. 334-340, 2009.

[19] U. Gündel, D. Benndorf, M. Von Bergen, R. Altenburger, and E. Küster, "Vitellogenin cleavage products as indicators for toxic stress in zebra fish embryos: a proteomic approach," Proteomics, vol. 7, no. 24, pp. 4541-4554, 2007.
[20] E. A. Shrader, T. R. Henry, M. S. Greeley Jr., and B. P. Bradley, "Proteomics in zebrafish exposed to endocrine disrupting chemicals," Ecotoxicology, vol. 12, no. 6, pp. 485-488, 2003.

[21] T. Ziv, T. Gattegno, V. Chapovetsky et al., "Comparative proteomics of the developing fish (zebrafish and gilthead seabream) oocytes," Comparative Biochemistry and Physiology $D$, vol. 3, no. 1, pp. 12-35, 2008.

[22] V. Link, A. Shevchenko, and C.-P. Heisenberg, "Proteomics of early zebrafish embryos," BMC Developmental Biology, vol. 6, pp. 1-9, 2006.

[23] T. L. Tay, Q. Lin, T. K. Seow, K. H. Tan, C. L. Hew, and Z. Gong, "Proteomic analysis of protein profiles during early development of the zebrafish, Danio rerio," Proteomics, vol. 6, no. 10, pp. 3176-3188, 2006.

[24] Y. Lin, Y. Chen, X. Yang, D. Xu, and S. Liang, "Proteome analysis of a single zebrafish embryo using three different digestion strategies coupled with liquid chromatographytandem mass spectrometry," Analytical Biochemistry, vol. 394, no. 2, pp. 177-185, 2009.

[25] M. B. Lucitt, T. S. Price, A. Pizarro et al., "Analysis of the zebrafish proteome during embryonic development," Molecular and Cellular Proteomics, vol. 7, no. 5, pp. 981-994, 2008.

[26] C. Wiegand, S. Pflugmacher, A. Oberemm, and C. Steinberg, "Activity development of selected detoxication enzymes during the ontogenesis of the zebrafish (Danio rerio)," International Review of Hydrobiology, vol. 85, no. 4, pp. 413-422, 2000.

[27] E. Küster, "Cholin- and carboxylesterase activities in developing zebrafish embryos (Danio rerio) and their potential use for insecticide hazard assessment," Aquatic Toxicology, vol. 75, no. 1, pp. 76-85, 2005.

[28] J. Riedl and R. Altenburger, "Physicochemical substance properties as indicators for unreliable exposure in microplatebased bioassays," Chemosphere, vol. 67, no. 11, pp. 2210-2220, 2007.

[29] R. Schreiber, R. Altenburger, A. Paschke, and E. Küster, "How to deal with lipophilic and volatile organic substances in microtiter plate assays," Environmental Toxicology and Chemistry, vol. 27, no. 8, pp. 1676-1682, 2008.

[30] A. Görg, W. Postel, J. Weser et al., "Elimination of point streaking on silver stained two-dimensional gels by addition of iodoacetamide to the equilibration buffer," Electrophoresis, vol. 8, pp. 122-124, 1987.

[31] J. Heukeshoven and R. Dernick, "Improved silver staining procedure for fast staining in Phast-System Development Unit. I. Staining of sodium dodecyl sulfate gels," Electrophoresis, vol. 9, no. 1, pp. 28-32, 1988.

[32] J. X. Yan, R. Wait, T. Berkelman et al., "A modified silver staining protocol for visualization of proteins compatible with matrix-assisted laser desorption/ionization and electrospray ionization-mass spectrometry," Electrophoresis, vol. 21, no. 17, pp. 3666-3672, 2000.

[33] D. Benndorf, N. Loffhagen, and W. Babel, "Chemicals and heat generate different protein patterns in Acinetobacter calcoaceticus," Journal of Basic Microbiology, vol. 37, no. 3, pp. 167-174, 1997.

[34] F. Schuler and J. E. Casida, "Functional coupling of PSST and ND1 subunits in NADH:ubiquinone oxidoreductase established by photoaffinity labeling," Biochimica et Biophysica Acta, vol. 1506, no. 1, pp. 79-87, 2001.

[35] A. F. Pelfrène, "Dinitro-ortho-Cresol," World Health Organisation, 2000, https://apps.who.int/pcs/ehc/full-text/ehc220 .pdf. 
[36] J. R. Vane and R. M. Botting, "New insights into the mode of action of anti-inflammatory drugs," Inflammation Research, vol. 44, no. 1, pp. 1-10, 1995.

[37] T. Monsinjon and T. Knigge, "Proteomic applications in ecotoxicology," Proteomics, vol. 7, no. 16, pp. 2997-3009, 2007.

[38] T. Terranova, T. Galeotti, and S. Baldi, "Der Einfluß von 2deoxy-D-glucose und Rotenon auf den energetischen Stoffwechsel und auf den Energieverbrauch in Ehrlich-AscitesCarcinomzellen," Zeitschrift für Krebsforschung, vol. 67, no. 3, pp. 255-261, 1965.

[39] A. Locker, H. Siedek, and K. H. Spitzy, "Zur Wirkung von Dinitrokresol und Thiouracil auf den Zellstoffwechsel," Archiv für Experimentelle Pathologie und Pharmakologie, vol. 210, no. 3, pp. 281-288, 1950.

[40] S. Kennedy, "The role of proteomics in toxicology: identification of biomarkers of toxicity by protein expression analysis," Biomarkers, vol. 7, no. 4, pp. 269-290, 2002.

[41] U. A. Boelsterli, Mechanistic Toxicology-The Molecular Basis of how Chemicals Disrupt Biological Targets, CRC Press, Boca Raton, Fla, USA, 2nd edition, 2003.

[42] J. L. Shepard and B. P. Bradley, "Protein expression signatures and lysosomal stability in Mytilus edulis exposed to graded copper concentrations," Marine Environmental Research, vol. 50, no. 1-5, pp. 457-463, 2000.

[43] J. L. Shepard, B. Olsson, M. Tedengren, and B. P. Bradley, "Protein expression signatures identified in Mytilus edulis exposed to PCBs, copper and salinity stress," Marine Environmental Research, vol. 50, no. 1-5, pp. 337-340, 2000.

[44] T. Knigge, T. Monsinjon, and O.-K. Andersen, "Surfaceenhanced laser desorption/ionization-time of flight-mass spectrometry approach to biomarker discovery in blue mussels (Mytilus edulis) exposed to polyaromatic hydrocarbons and heavy metals under field conditions," Proteomics, vol. 4, no. 9, pp. 2722-2727, 2004.

[45] J. Jin, J. Davis, D. Zhu et al., "Identification of novel proteins affected by rotenone in mitochondria of dopaminergic cells," BMC Neuroscience, vol. 8, Article ID 67, pp. 1-14, 2007.

[46] J. Bové, D. Prou, C. Perier, and S. Przedborski, “Toxin-induced models of Parkinson's disease," NeuroRx, vol. 2, no. 3, pp. 484494, 2005.

[47] W. W. Cheng and A. P. Farrell, "Acute and sublethal toxicities of rotenone in juvenile rainbow trout (Oncorhynchus mykiss): swimming performance and oxygen consumption," Archives of Environmental Contamination and Toxicology, vol. 52, no. 3, pp. 388-396, 2007.

[48] B. R. Brinkley, S. S. Barham, S. C. Barranco, and G. M. Fuller, "Rotenone inhibition of spindle microtubule assembly in mammalian cells," Experimental Cell Research, vol. 85, no. 1, pp. 41-46, 1974.

[49] Y. Miura, M. Kano, K. Abe, S. Urano, S. Suzuki, and T. Toda, "Age-dependent variations of cell response to oxidative stress: proteomic approach to protein expression and phosphorylation," Electrophoresis, vol. 26, no. 14, pp. 2786-2796, 2005.

[50] H. Manduzio, P. Cosette, L. Gricourt et al., "Proteome modifications of blue mussel (Mytilus edulis L.) gills as an effect of water pollution," Proteomics, vol. 5, no. 18, pp. 49584963, 2005.

[51] J. Ravneet, M. S. Johal, and M. L. Sharma, "Three-dimensional study on the effect of organophosphate pesticide 'monocrotophos' on lens of fish and its recovery," Veterinary Ophthalmology, vol. 12, no. 3, pp. 152-157, 2009. 

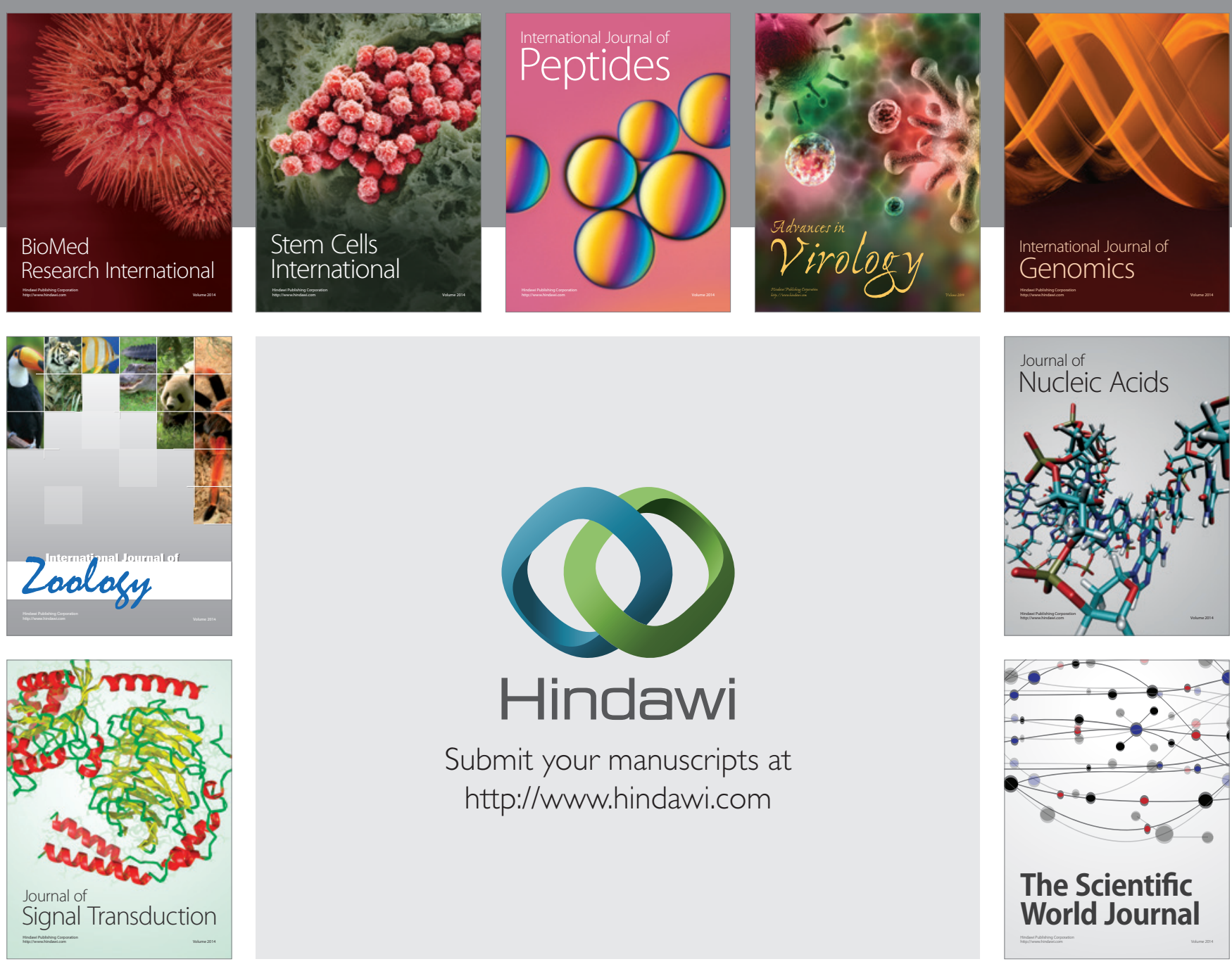

Submit your manuscripts at

http://www.hindawi.com
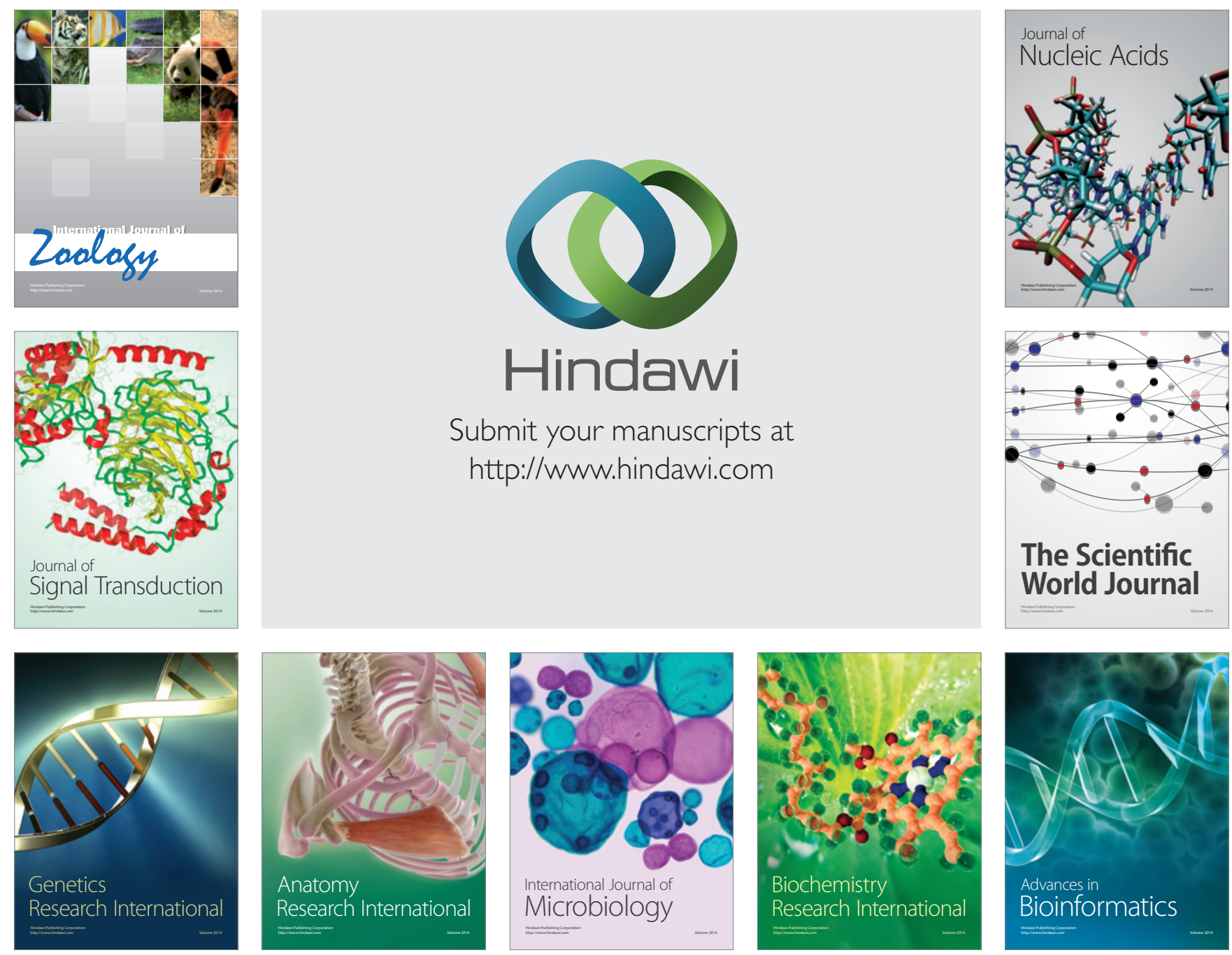

The Scientific World Journal
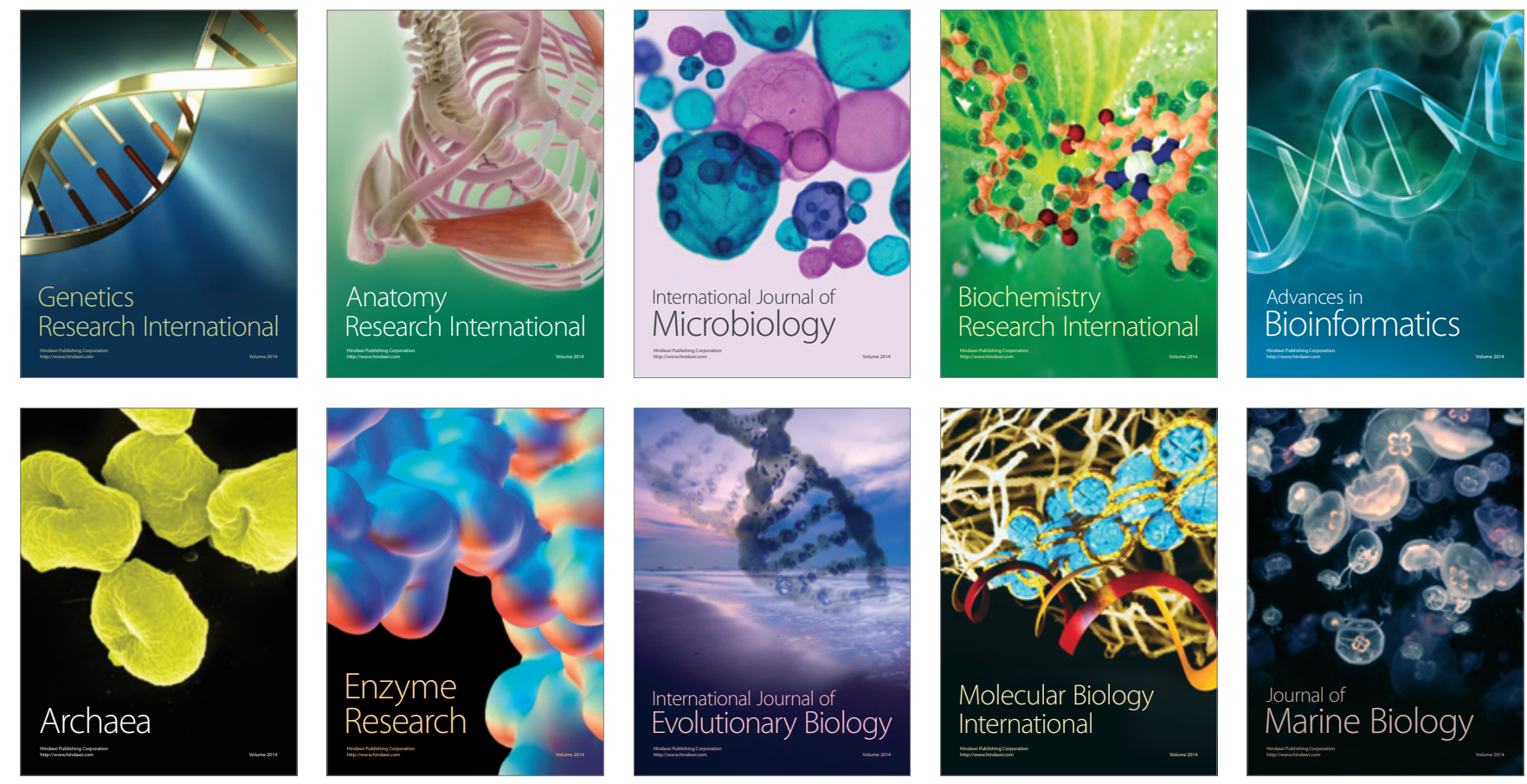